OPEN ACCESS

Edited by:

Christina Magnussen, University Heart and Vascular Center Hamburg (UHZ), Germany

Reviewed by:

Christoph Sinning,

University Heart and Vascular Center Hamburg (UHZ), Germany

Daniel Reichart, Harvard Medical School, United States

*Correspondence: Hoa Ngoc Chau

hoachau@ump.edu.vn Minh Duc Do

ducminh@ump.edu.vn

tThese authors have contributed equally to this work

Specialty section:

This article was submitted to Cardiovascular Genetics and Systems

Medicine,

a section of the journal Frontiers in Cardiovascular Medicine

Received: 22 September 2020 Accepted: 06 January 2021

Published: 19 February 2021

Citation:

Tran TT, Mai TP, Tran HCB, Le LHG, Vu HA, Tran TK, Hoang SV, Chau HN and Do MD (2021) Association Between AGT M235T and Left Ventricular Mass in Vietnamese

Patients Diagnosed With Essential Hypertension Front. Cardiovasc. Med. 8:608948. doi: 10.3389/fcvm.2021.608948

\section{Association Between AGT M235T and Left Ventricular Mass in Vietnamese Patients Diagnosed With Essential Hypertension}

Tuan Thanh Tran ${ }^{1 \dagger}$, Thao Phuong Mai ${ }^{2 \dagger}$, Ha Chau Bich Tran ${ }^{3}$, Linh Hoang Gia Le ${ }^{4}$, Hoang Anh Vu ${ }^{4}$, Trang Kim Tran ${ }^{1}$, Sy Van Hoang ${ }^{1}$, Hoa Ngoc Chau ${ }^{1 * t}$ and Minh Duc Do ${ }^{4 * t}$

${ }^{1}$ Department of Internal Medicine, Faculty of Medicine, University of Medicine and Pharmacy at Ho Chi Minh City, Ho Chi Minh City, Vietnam, ${ }^{2}$ Department of Physiology-Pathophysiology-Immunology, Faculty of Medicine, University of Medicine and Pharmacy at Ho Chi Minh City, Ho Chi Minh City, Vietnam, ${ }^{3}$ Center for Cardiovascular Medicine, University Medical Center, Ho Chi Minh City, Vietnam, ${ }^{4}$ Center for Molecular Biomedicine, University of Medicine and Pharmacy at Ho Chi Minh City, Ho Chi Minh City, Vietnam

Background: Increasing left ventricular mass in hypertensive patients is an independent prognostic marker for adverse cardiovascular outcomes. Genetic factors have been shown to critically affect left ventricular mass. AGT M235T is one of the genetic polymorphisms that may influence left ventricular mass due to its pivotal role in the regulation of plasma angiotensinogen level as well as hypertension pathophysiology in Asian populations. Currently, how M235T affects left ventricular mass is not well-described in Vietnamese hypertensive patients. This study aimed to investigate the association between M235T and left ventricular mass in Vietnamese patients diagnosed with essential hypertension.

Materials and Methods: AGT M235T genotyping and 2D echocardiography were performed on 187 Vietnamese subjects with essential hypertension. All the ultrasound parameters were obtained to calculate the left ventricular mass index according to the American Society of Echocardiography and the European Association of Cardiovascular Imaging 2015 guidelines. Other clinical characteristics were also recorded, including age, gender, duration of hypertension, hypertensive treatment, lifestyle, renal function, fasting plasma glucose, and lipid profile.

Results: MT and TT genotypes were determined in 30 and 157 subjects, respectively. AGT M235T genotype, duration of hypertension, body mass index, and ejection fraction statistically affected the left ventricular mass index, which was significantly greater in TT compared to MT carriers after adjusting for confounding factors.

Conclusion: The $\Pi T$ genotype of AGT M23T was associated with greater left ventricular mass in Vietnamese patients diagnosed with essential hypertension.

Keywords: essential hypertension, echocardiography, left ventricular mass, Vietnam, AGT M235T 


\section{INTRODUCTION}

Essential hypertension is a major health-care burden globally, despite the availability of efficient antihypertensive agents (1). Increasing left ventricular mass (LVM) identified by echocardiography in hypertensive patients has been well-proven to be a strong independent predictor of adverse cardiovascular outcomes, including sudden cardiac death, coronary artery diseases, stroke, and heart failure (2). Besides the severity and duration of hypertension, plenty of other factors have been found to affect LVM, including age, gender, ethnicity, and genetic elements, as well as comorbidities such as obesity, diabetes, and chronic kidney disease $(3,4)$.

Genetic components have been shown to be associated with LVM in hypertensive patients (5-8). Variants of renin-angiotensin-aldosterone (RAA) genes have attracted an enormous amount of attention due to the important physiological roles of the RAA system (9). The RAA hormonal system regulates blood pressure and fluid and electrolyte balance, together with vascular resistance (10). Angiotensinogen (AGT) is first fragmented by renin to produce angiotensin $\mathrm{I}$, the angiotensin-converting enzyme (ACE) then converts angiotensin I to the active form angiotensin II. Angiotensin II binds to receptors leading to the synthesis of aldosterone, which promotes the reabsorption of water and salt in the renal tubes (11). The RAA system affects LVM not only indirectly through blood pressure but also directly by the action of angiotensin II on cardiomyocytes (12). Numerous studies have been conducted to elucidate the association between RAA genetic polymorphisms and LVM (13-15). Among candidate variants, $A G T$ M235T is one of the more promising markers showing an association with LVM in hypertensive patients. AGT M235T is characterized by the substitution of Threonine for Methionine in codon 235, and is well-proven to affect the plasma angiotensinogen concentration (16). Interestingly, the $\mathrm{T}$ allele of M235T, which is related to higher plasma AGT, is well-associated with hypertension in Africans and Asians, such as Nigerian, Egyptian, Malaysian, and Japanese populations (17-21), but this association remains controversial in Caucasians (22-24). Similarly, the unfavorable effects of the $\mathrm{T}$ allele in increasing LVM have been observed in Chinese but not Russians or Americans (25-27). Mechanisms that underlie how AGT M235T affects LVM are still elusive. One possibility is the greater plasma AGT level in TT-carriers resulting in an excessive amount of angiotensin II, which regulates the growth of cardiomyocytes independently of blood pressure (28). Another possibility is the linkage disequilibrium between M235T and other driving variants leading to the increase in LVM.

\footnotetext{
Abbreviations: ACE, angiotensin-converting enzyme; AGT, angiotensinogen; BMI, body mass index; BSA, body surface area; EF, ejection fraction; GFR, glomerular filtration rate; IVSd, interventricular septal thickness at end-diastole; IVSs, interventricular septal thickness in systole; LPWd, posterior wall thickness at end-diastole; LPWs, posterior wall thickness in systole; LVIDd, left ventricular internal dimension at end-diastole; LVIDs, left ventricular internal dimension in systole; LVM, left ventricular mass; LVMI, left ventricular index; RAA, reninangiotensin-aldosterone; RWT, relative wall thickness.
}

So far, the association between RAA genetic variants and LVM in Vietnamese hypertensive patients has not been elucidated. This study aimed to identify the association between AGT M235T and LVM in Vietnamese patients diagnosed with essential hypertension.

\section{MATERIALS AND METHODS}

\section{Subjects}

This study was approved by the Ethical Committee of the University of Medicine and Pharmacy at Ho Chi Minh City, Vietnam. Patients, either newly diagnosed or previously diagnosed with essential hypertension and on antihypertensive agents were recruited to this study, which took place in the University Medical Center between January 2019 and May 2019. All patients were self-identified as Kinh Vietnamese and were randomly selected with $\mathrm{k}=10$ from the daily registered list for cardiovascular examination. Patients were excluded from the study if they had been diagnosed with diabetes or had a history of angina or myocardial infarction, or their estimated glomerular filtration rate was $<60 \mathrm{ml} / \mathrm{min} / 1.73 \mathrm{~m}^{2}$ of the body surface. The patients were counseled, and they agreed to participate in the study by providing written informed consent. The age, gender, height, and body weight of the patients were recorded. Body weight was measured using digital scales (HN289; Omron, Tokyo, Japan) in clothing without shoes. Height was determined without shoes on a wall-mounted stadiometer (HM200PW; Charder Medical, Taichung, Taiwan) with mandible plane parallel to the floor. Body mass index (BMI) was calculated as weight $(\mathrm{kg})$ divided by the square of height $(\mathrm{m})(29)$; body surface area was estimated by the square root of the height $(\mathrm{cm})$ multiplied by the weight $(\mathrm{kg})$ divided by 3,600 (30). All information including age at hypertension diagnosis, duration of hypertension, antihypertensive medication, high-salt diet, smoking, alcohol use, exercise, family history of hypertension, and later, blood pressure and echocardiography parameters, were documented. A high-salt diet was assessed using the questionnaire developed by the Salt Consumption Survey in the Republic of Moldova Study Group (31). Alcohol use and smoking were assessed using the WHO STEPS Instrument for non-communicable diseases Risk Factor Surveillance (32). Blood pressure was measured automatically by a digital sphygmomanometer (JPN600, Omron, Tokyo, Japan). Newly diagnosed hypertensive patients were identified based on the diagnostic criteria of the European Society of Cardiology and the European Society of Hypertension 2018 guidelines for the management of arterial hypertension (33). For hypertensive patients who were equal to or $<35$ years old, renal artery ultrasound, abdominal ultrasound, blood electrolyte, thyroidstimulating hormone, plasma renin and aldosterone, 24-h urinary catecholamine, and cortisol tests were performed to investigate the hypertensive etiology. If any result of these tests was abnormal, the participant was excluded. Hypertensive patients who were $>35$ years old were excluded from the study if they were suspected of having secondary hypertension, based on their history and a physical examination. For newly diagnosed patients, a cardiac ultrasound was performed 
only when the hypertensive diagnosis was determined in the second visit. Following the cardiac ultrasound, patients with moderate to severe valvular heart disease, moderate to severe pulmonary hypertension, hypertrophic cardiomyopathy, myocardial ischemia [defined as abnormalities in wall motion (hypokinesia/akinesia)], aneurysm, or ejection fraction $(\mathrm{EF})<$ $55 \%$ were also excluded from the study. Finally, $2 \mathrm{~mL}$ of venous blood was drawn from 187 of the participants for genetic analysis. Other laboratory measurements were obtained, such as fasting plasma glucose $(\mathrm{mg} / \mathrm{dl})$, estimated glomerular filtration rate (GFR) from serum creatinine, total cholesterol $(\mathrm{mmol} / \mathrm{L})$, HDL-cholesterol (mmol/L), LDL-cholesterol $(\mathrm{mmol} / \mathrm{L})$, and triglyceride $(\mathrm{mmol} / \mathrm{L})$.

\section{Echocardiography}

Two-dimensionally guided M-mode echocardiography was performed using the Affiniti 50G ultrasound system (Philips, Amsterdam, The Netherlands) with a 2-4 MHz transducer at the Cardiology Imaging Unit of the University Medical Center at Ho Chi Minh City. All the echocardiography parameters used for further analysis were the average of two measurements obtained blindly by two independent cardiologists with proper echocardiographical expertise according to the recommendations of the American Society of Echocardiography and the European Association of Cardiovascular Imaging 2015 guidelines $(34,35)$. Left ventricular parameters, such as left ventricular internal dimension at end-diastole (LVIDd) and in systole (LVIDs), posterior wall thickness at end-diastole (LPWd) and in systole (LPWs), and interventricular septal thickness at end-diastole (IVSd) and in systole (IVSs) were measured for three beats, and average values were collected for further calculations. LVM was calculated from the measurements of the left ventricle $(\mathrm{LV})$ using the equation: $\mathrm{LVM}=\left((\mathrm{IVSd}+\mathrm{LVDd}+\mathrm{LPWd})^{3}\right.$ $\left.(\mathrm{LVDd})^{3}\right) \times 1.04 \times 0.8+0.6(\mathrm{~g})$. LVMI (left ventricular mass index) was identified by the formula: LVMI $=\mathrm{LVM} / \mathrm{BSA}\left(\mathrm{g} / \mathrm{m}^{2}\right)$. Left ventricular hypertrophy was defined as LVMI $>115 \mathrm{~g} / \mathrm{m}^{2}$ for men or $95 \mathrm{~g} / \mathrm{m}^{2}$ in women (34). Relative wall thickness (RWT) was calculated with the formula RWT $=2 \mathrm{xLPWd} / \mathrm{LVDd}$. RWT was considered abnormal if it was $>0.42$. Four left ventricular geometric patterns were identified based on RWT and LVMI: normal geometry, concentric remodeling, eccentric hypertrophy, and concentric hypertrophy. LV geometry was defined as concentric hypertrophy (elevated LVMI and RWT), concentric remodeling (normal LVMI and elevated RWT), eccentric hypertrophy (increased LVMI and normal RWT), and normal geometry (normal LVMI and RWT). EF was assessed using the Teichholz method (36). Supplementary Figure 1 represents how echocardiography measurements were documented.

\section{Genetic Analysis}

Genomic DNA was extracted from patients' leukocytes using a GeneJet $^{\mathrm{TM}}$ Whole Blood Genomic DNA Purification Mini Kit (Thermo Fisher Scientific, Waltham, MA, USA). Four primers were designed for a tetra-primer allele-specific polymerase chain reaction (PCR) to identify $\mathrm{M} 235 \mathrm{~T}$ based on the sequence of the AGT gene (Genebank NG_008836). The length of control bands was $282 \mathrm{bp}$. Allele $\mathrm{T}$ and allele $\mathrm{M}$ were determined by the appearance of 118 bp and 204 bp bands, respectively. The sequences of primers are listed in Supplementary Table 1.

PCRs were performed using a Mastercycler@proS (Eppendorf, Hamburg, Germany) with the following conditions: one cycle at $98^{\circ} \mathrm{C}$ for $3 \mathrm{~min}$ and 40 cycles of denaturation at $98^{\circ} \mathrm{C}$ for $20 \mathrm{~s}$, annealing at $56^{\circ} \mathrm{C}$ for $20 \mathrm{~s}$, extension at $72^{\circ} \mathrm{C}$ for $30 \mathrm{~s}$, and final extension at $72^{\circ} \mathrm{C}$ for $2 \mathrm{~min}$. The product length of PCR was identified by electrophoresis on $2 \%$ agarose gels with Diamond ${ }^{\mathrm{TM}}$ Nucleic Acid Dye (Promega, Madison, WI, USA).

\section{Data Analysis}

The data were encrypted to ensure blinded analysis. Data were input using Epidata 3.1 and subsequently analyzed using Stata 13.3 software. T-test and Chi-squared tests were performed for statistical analysis. Univariate analysis and multivariate logistic regression were used to assess the association between patients' characteristics and LVMI. All tests were considered significant if $p \leq 0.05$.

\section{RESULTS}

TT, MT, and MM genotypes of AGT M235T were found in 157, 30, and 0 individuals, respectively. The percentage of $\mathrm{T}$ and $\mathrm{M}$ alleles were 92 and $8 \%$. The distribution of $A G T$ M235T was under Hardy Weinberg equilibrium, with $p=0.49$. Patients' characteristics are described in Table 1. The mean age of the participants was 46, with an average duration of essential hypertension of 3.5 years. Males comprised $55 \%$ of the population studied. All the clinical and laboratory characteristics were not significantly different between MT and TT-genotyped participants, except for triglyceride concentration and alcohol usage. Factors that were known to influence LVM, including age, gender, treatment with ACE inhibitors or angiotensin II receptor blockers, BMI, and eGFR, were not statistically different between the two genotypes.

Echocardiography parameters are listed in Table 2. All the measures were not statistically different between TT and MT genotypes, except for LVMI, which was significantly greater in TT compared to MT-carrying subjects. The distribution of left ventricular geometric patterns is listed in Table 3. No significant differences were found in left ventricular geometric patterns between the genotypes. The majority of LV geometric patterns were normal in both MT and TT groups.

Univariate analysis showed that the duration of hypertension, genotype, BMI, and EF were significantly correlated with LVMI (Tables 4, 5). After adjusting by multivariate logistic regression, M235T remained statistically associated with LVMI, and TTcarrying subjects presented an average $8.6\left(\mathrm{~g} / \mathrm{m}^{2}\right)$ higher LVMI than MT-carrying subjects (Table 6).

\section{DISCUSSION}

Echocardiography is a reliable, cost-effective imaging technique to determine LVM. Its adoption has been extensively certified in clinical practice, as well as research $(37,38)$. In this study, AGT M235T, duration of hypertension, BMI, and EF were found to be associated with calculated LVMI in Vietnamese 
TABLE 1 | Characteristics of hypertensive patients by M235T genotypes.

\begin{tabular}{|c|c|c|c|c|}
\hline Characteristics & $\begin{array}{l}\text { Population } \\
(n=187)\end{array}$ & $\begin{array}{c}\text { MT } \\
(n=30)\end{array}$ & $\begin{array}{c}\text { TT } \\
(n=157)\end{array}$ & $P$-value \\
\hline $\begin{array}{l}\text { Age (years) } \\
(\text { Mean } \pm S D)\end{array}$ & $46.0 \pm 9.5$ & $44.0 \pm 9.9$ & $46.4 \pm 9.4$ & 0.25 \\
\hline Male gender (\%) & $55.1 \%$ & $43.3 \%$ & $57.3 \%$ & 0.16 \\
\hline $\begin{array}{l}\text { Age at diagnosis (years) } \\
\text { (Mean } \pm \text { SD) }\end{array}$ & $42.5 \pm 9.8$ & $40.6 \pm 11.4$ & $42.9 \pm 9.4$ & 0.24 \\
\hline $\begin{array}{l}\text { Duration of hypertension } \\
\text { (years) } \\
\text { (Mean } \pm \text { SD) }\end{array}$ & $3.5 \pm 4.3$ & $3.6 \pm 3.6$ & $3.5 \pm 4.4$ & 0.91 \\
\hline $\begin{array}{l}\text { Use of antihypertensive } \\
\text { medication (\%) }\end{array}$ & $83.4 \%$ & $86.7 \%$ & $82.8 \%$ & 0.60 \\
\hline ACE inhibitor (\%) & $17.7 \%$ & $16.0 \%$ & $18.1 \%$ & 1.00 \\
\hline $\begin{array}{l}\text { Angiotensin II receptor } \\
\text { blockers (\%) }\end{array}$ & $60.0 \%$ & $72.0 \%$ & $57.1 \%$ & 0.17 \\
\hline $\begin{array}{l}\text { Calcium channel blockers } \\
(\%)\end{array}$ & $57.7 \%$ & $44.0 \%$ & $61.0 \%$ & 0.12 \\
\hline Diuretics (\%) & $15.4 \%$ & $12.0 \%$ & $16.2 \%$ & 0.76 \\
\hline Beta-blockers (\%) & $22.3 \%$ & $36.0 \%$ & $19.1 \%$ & 0.07 \\
\hline $\begin{array}{l}\mathrm{BMl}\left(\mathrm{kg} / \mathrm{m}^{2}\right) \\
(\text { Mean } \pm \mathrm{SD})\end{array}$ & $24.4 \pm 2.8$ & $23.9 \pm 3.6$ & $24.5 \pm 2.6$ & 0.39 \\
\hline $\begin{array}{l}\mathrm{BSA}\left(\mathrm{m}^{2}\right) \\
(\text { Mean } \pm \mathrm{SD})\end{array}$ & $1.7 \pm 0.2$ & $1.7 \pm 0.2$ & $1.7 \pm 0.2$ & 0.26 \\
\hline High salt intake (\%) & $64.7 \%$ & $50.0 \%$ & $67.5 \%$ & 0.07 \\
\hline Smoking (\%) & $15.0 \%$ & $13.3 \%$ & $15.3 \%$ & 1.00 \\
\hline Alcohol usage (\%) & $48.1 \%$ & $26.7 \%$ & $52.2 \%$ & $0.01^{*}$ \\
\hline Sedentary lifestyle (\%) & $65.8 \%$ & $76.7 \%$ & $63.7 \%$ & 0.17 \\
\hline $\begin{array}{l}\text { Family history of } \\
\text { hypertension (\%) }\end{array}$ & $71.7 \%$ & $70.0 \%$ & $72.0 \%$ & 0.83 \\
\hline $\begin{array}{l}\text { Fasting plasma glucose } \\
(\mathrm{mg} / \mathrm{dl}) \\
\text { (Mean } \pm \mathrm{SD})\end{array}$ & $98.2 \pm 10.6$ & $98.4 \pm 10.6$ & $98.2 \pm 10.6$ & 0.94 \\
\hline $\begin{array}{l}\text { eGFR }\left(\mathrm{ml} / \mathrm{min} / 1.73 \mathrm{~m}^{2}\right) \\
(\text { Mean } \pm \mathrm{SD})\end{array}$ & $83.8 \pm 13.0$ & $85.3 \pm 17.8$ & $83.5 \pm 12.0$ & 0.60 \\
\hline $\begin{array}{l}\text { Total cholesterol (mmol/L) } \\
\text { (Mean } \pm \text { SD) }\end{array}$ & $5.5 \pm 1.3$ & $5.3 \pm 1.2$ & $5.5 \pm 1.3$ & 0.39 \\
\hline $\begin{array}{l}\text { HDL cholesterol (mmol/L) } \\
\text { (Mean } \pm \text { SD) }\end{array}$ & $1.2 \pm 0.3$ & $1.2 \pm 0.3$ & $1.2 \pm 0.3$ & 0.88 \\
\hline $\begin{array}{l}\text { LDL cholesterol (mmol/L) } \\
\text { (Mean } \pm \text { SD) }\end{array}$ & $3.6 \pm 0.9$ & $3.5 \pm 0.9$ & $3.6 \pm 0.9$ & 0.67 \\
\hline $\begin{array}{l}\text { Triglyceride }(\mathrm{mmol} / \mathrm{L}) \\
(\text { Mean } \pm \mathrm{SD})\end{array}$ & $2.5 \pm 1.8$ & $1.9 \pm 0.8$ & $2.6 \pm 1.9$ & $0.00^{\star}$ \\
\hline
\end{tabular}

BMI, body mass index; BSA, body surface area; eGFR, estimated glomerular filtration rate. *statistically significant.

patients diagnosed with essential hypertension. Factors that were considered to affect LVM, including age, gender, duration of hypertension, use of ACE inhibitors or angiotensin II receptor blockers, BMI, body surface area (BSA), and eGFR were not statistically different between TT and MT carriers. LVMI was significantly higher in TT compared to MT-carrying subjects even after adjusting for confounding factors, such as duration of hypertension, EF, and BMI. A similar association between M235T and LVM has been observed in Han Chinese (25) but not Russian and American populations $(26,27)$. The allele distribution of AGT M235T in Vietnamese hypertensive patients is similar to
TABLE 2 | M-mode echocardiographic measures in hypertensive patients by M235T genotypes.

\begin{tabular}{lcccc}
\hline $\begin{array}{l}\text { Measures } \\
\text { (Mean } \pm \text { SD) }\end{array}$ & $\begin{array}{c}\text { Population } \\
(\boldsymbol{n}=\mathbf{1 8 7})\end{array}$ & $\begin{array}{c}\text { MT } \\
(\boldsymbol{n}=\mathbf{3 0})\end{array}$ & $\begin{array}{c}\text { TT } \\
(\boldsymbol{n}=\mathbf{1 5 7})\end{array}$ & P-value \\
\hline IVSd $\left(\mathrm{mm} / \mathrm{m}^{2}\right)$ & $5.5 \pm 1.0$ & $5.3 \pm 1.2$ & $5.6 \pm 1.0$ & 0.13 \\
IVSs $\left(\mathrm{mm} / \mathrm{m}^{2}\right)$ & $7.7 \pm 1.3$ & $7.3 \pm 1.5$ & $7.8 \pm 1.2$ & 0.08 \\
LVIDd $\left(\mathrm{mm} / \mathrm{m}^{2}\right)$ & $28.1 \pm 3.0$ & $28.4 \pm 3.1$ & $28.0 \pm 3.0$ & 0.58 \\
LVIDs $\left(\mathrm{mm} / \mathrm{m}^{2}\right)$ & $17.3 \pm 2.3$ & $17.4 \pm 1.9$ & $17.2 \pm 2.3$ & 0.68 \\
LPWd $\left(\mathrm{mm} / \mathrm{m}^{2}\right)$ & $5.5 \pm 1.0$ & $5.3 \pm 1.1$ & $5.6 \pm 1.0$ & 0.22 \\
LPWs $\left(\mathrm{mm} / \mathrm{m}^{2}\right)$ & $8.5 \pm 1.5$ & $8.5 \pm 1.4$ & $8.5 \pm 1.5$ & 0.77 \\
EF $(\%)$ & $68.7 \pm 5.8$ & $68.2 \pm 6.4$ & $68.8 \pm 5.7$ & 0.61 \\
LVMI $\left(\mathrm{g} / \mathrm{m}^{2}\right)$ & $89.7 \pm 20.9$ & $82.4 \pm 20.4$ & $91.1 \pm 20.7$ & $0.04^{*}$ \\
\hline
\end{tabular}

EF, ejection fraction; IVSd, interventricular septal thickness at end-diastole; IVSs, interventricular septal thickness in systole; LVIDd, left ventricular internal dimension at end-diastole; LVIDs, left ventricular internal dimension in systole; LPWd, posterior wall thickness at end-diastole; LPWs, posterior wall thickness in systole; LVMI, left ventricular index.

*statistically significant.

TABLE 3 | Left ventricular geography in hypertensive patients with AGT genotypes.

\begin{tabular}{|c|c|c|c|c|}
\hline Geometric pattern & $\begin{array}{l}\text { Population } \\
(n=187)\end{array}$ & $\begin{array}{c}\text { MT } \\
(n=30)\end{array}$ & $\begin{array}{c}\text { TT } \\
(n=157)\end{array}$ & $P$-value \\
\hline Normal & $49 \%(n=92)$ & $57 \%(n=17)$ & $47 \%(n=74)$ & 0.82 \\
\hline Concentric remodeling & $28 \%(n=52)$ & $27 \%(n=8)$ & $28 \%(n=44)$ & \\
\hline Concentric hypertrophy & $11 \%(n=21)$ & $6 \%(n=2)$ & $12 \%(n=19)$ & \\
\hline Eccentric hypertrophy & $12 \%(n=22)$ & $10 \%(n=3)$ & $13 \%(n=20)$ & \\
\hline
\end{tabular}

Nigerian patients, in whom the frequency of the $\mathrm{M}$ allele is < $10 \%$ (17). The frequency of the $\mathrm{M}$ allele is $16 \%$ in Chinese, $19 \%$ in Japanese, $44 \%$ in Rumanian, and up to $67 \%$ in German hypertensive populations $(18,22,24,39)$. The predominance of the $\mathrm{T}$ allele and the profound association between the TT genotype and adverse cardiovascular phenotypes seem to be signature characteristics of Asian populations whose similarity in genetic landscapes has been reported (40-42). The TT genotype is also associated with a higher prevalence of hypertension in Malaysian and Japanese populations, but not Caucasians (18, 19, 24). Interestingly, a recent meta-analysis showed that the T allele is associated with cardiovascular diseases, including essential hypertension, myocardial infarction, and coronary artery disease in East Asians but not Caucasians (43). In addition to the effect on cardiomyocytes described above, greater level of Angiotensin II in TT carriers also affects endothelial cell function by multiple pathways, including promoting endothelial cell apoptosis, increasing vascular endothelial growth factor, and compromising nitric oxide production (44). These biological changes, in part, could explain why the $\mathrm{T}$ allele of M235T is associated with higher risk of essential hypertension, coronary artery disease, and heart failure, as well as mortality due to heart failure (45-47). However, these associations were inconsistent between ethnicities, and the mechanism underlying how M235T affects 
TABLE 4 | The association between categorical variables and LVMI.

\begin{tabular}{|c|c|c|}
\hline Variables & LVMI (mean \pm SD) & $P$-value \\
\hline Gender & & 0.30 \\
\hline Male & $90.4 \pm 20.2$ & \\
\hline Female & $88.8 \pm 21.9$ & \\
\hline Use of antihypertensive medication & & 0.19 \\
\hline Yes & $90.2 \pm 21.2$ & \\
\hline No & $86.8 \pm 18.9$ & \\
\hline Use of ACE inhibitor & & 0.30 \\
\hline Yes & $87.7 \pm 17.6$ & \\
\hline No & $89.9 \pm 21.2$ & \\
\hline Use of angiotensin II receptor blockers & & 0.21 \\
\hline Yes & $88.3 \pm 19.9$ & \\
\hline No & $91.3 \pm 21.5$ & \\
\hline Use of calcium channel blockers & & 0.22 \\
\hline Yes & $90.7 \pm 19.9$ & \\
\hline No & $87.8 \pm 21.4$ & \\
\hline Use of diuretic & & 0.15 \\
\hline Yes & $85.2 \pm 19.3$ & \\
\hline No & $90.3 \pm 20.7$ & \\
\hline Use of beta-blockers & & 0.20 \\
\hline Yes & $92.4 \pm 21.6$ & \\
\hline No & $88.7 \pm 20.3$ & \\
\hline High salt intake & & 0.051 \\
\hline Yes & $91.5 \pm 21.4$ & \\
\hline No & $86.4 \pm 19.5$ & \\
\hline Alcohol use & & 0.09 \\
\hline Yes & $91.7 \pm 21.1$ & \\
\hline No & $87.6 \pm 20.5$ & \\
\hline Smoking & & 0.39 \\
\hline Yes & $88.6 \pm 22.5$ & \\
\hline No & $89.8 \pm 20.6$ & \\
\hline Sedentary lifestyle & & 0.32 \\
\hline Yes & $88.7 \pm 20.4$ & \\
\hline No & $90.2 \pm 21.2$ & \\
\hline
\end{tabular}

$A C E$, angiotensin-converting enzyme.

such cardiovascular diseases remains poorly understood (48). Remarkably, M235T does not directly regulate the transcription of $A G T$ because it was proven not a hyperfunctional variant by expression study (49). The main driven variant controlling AGT transcription is $\mathrm{A}(-6) \mathrm{G}$. This variant, which is in strong linkage with M235T, is located in the promoter region of AGT and has been shown to be the key player in regulating $A G T$ transcription (49). The lack of linkage disequilibrium between M235T and $A(-6) G$, therefore, may explain the inconsistent association between M235T and essential hypertension, coronary artery disease among certain ethnicities.

It has been proposed that the major $\mathrm{T}$ allele is associated with the upregulation of the angiotensinogen level and promotes sodium reabsorption, while the minor $M$ allele is a recent "thrifty" mutation in humans to adapt to environmental changes in which sodium becomes widely available (50). The gradual
TABLE 5 | Univariate analysis between continuous variables and LVMI.

\begin{tabular}{lcc}
\hline Variables & R for correlation with LVMI & $\boldsymbol{P}$-value \\
\hline Genotype & 0.152 & $0.037^{\star}$ \\
BMI & 0.180 & $0.014^{\star}$ \\
Fasting plasma glucose & 0.045 & 0.538 \\
eGFR & 0.096 & 0.193 \\
Total cholesterol & 0.086 & 0.857 \\
HDL cholesterol & 0.059 & 0.421 \\
LDL cholesterol & 0.002 & 0.980 \\
Triglyceride & 0.033 & 0.653 \\
EF & 0.248 & $0.001^{*}$ \\
Duration of hypertension & 0.229 & $0.002^{*}$ \\
\hline
\end{tabular}

*statistically significant.

TABLE 6 | Multivariate logistic regression analysis of LVMI.

\begin{tabular}{lrr}
\hline Variables & LVMI & $P$-value \\
\hline TT vs. MT $\left(\mathrm{g} / \mathrm{m}^{2}\right)$ & $8.6 \pm 3.9$ & $0.027^{*}$ \\
Duration of hypertension (years) & $1.1 \pm 0.3$ & $0.001^{*}$ \\
BMl $\left(\mathrm{kg} / \mathrm{m}^{2}\right)$ & $1.1 \pm 0.5$ & $0.041^{*}$ \\
EF $(\%)$ & $-0.9 \pm 0.2$ & $<0.001^{*}$
\end{tabular}

*statistically significant.

increase in the frequency of the $\mathrm{M}$ allele in African, Southeast Asian, East Asian, and European populations may support the hypothesis that human ancestors originating from Africa migrated to Asia and then Europe (51). During the migration, the evolving "thrifty" $\mathrm{M}$ allele might have appeared and expanded. Together with the expansion of the $M$ allele, the unfavorable cardiovascular phenotypes of the T allele have been fading.

This study has several limitations that need to be discussed. First, the relatively small sample size may lead to a bias in identifying the $A G T$ M235T genotype in Vietnamese hypertensive subjects. Specifically, the MM genotype was not detectable in our data. Second, the measurement of LV by $2 \mathrm{D}$ ultrasound is less correlated with cardiac magnetic resonance in assessing LVM compared to real-time 3D echography (52). Third, like other polygenic models, the causative genetic factors affecting LVM are complex; AGT M235T per se cannot fully explain the difference in LVM between the genotype groups observed in this study. Therefore, further studies with larger sample sizes, comprehensive genetic analysis such as genomewide association or whole genome sequencing, and advanced imaging techniques are required to better describe the association between genetic components and LVM in Vietnamese patients with essential hypertension.

To the best of our knowledge, this is the first study to determine the association between genetic variants and LVM in Vietnamese patients diagnosed with essential hypertension. The association between AGT M235T and LVM in Vietnamese hypertensive patients emphasizes once again the significant effect of this genetic polymorphism in left ventricular hypertrophy pathophysiology in Asian populations. 


\section{DATA AVAILABILITY STATEMENT}

The original contributions presented in the study are included in the article/Supplementary Material, further inquiries can be directed to the corresponding author/s.

\section{ETHICS STATEMENT}

The studies involving human participants were reviewed and approved by Ethics Committee of the University of Medicine and Pharmacy at Ho Chi Minh City, Vietnam. The patients/participants provided their written informed consent to participate in this study.

\section{AUTHOR CONTRIBUTIONS}

MD, TT, TM, TKT, and HC designed the study. TT, $\mathrm{HT}$, and $\mathrm{SH}$ included the patients to the study. LL, HV, and TM performed genotyping procedure. MD, TT, HT, SH, TKT, and HC analyzed the data. MD, TT, and

\section{REFERENCES}

1. Forouzanfar MH, Liu P, Roth GA, Ng M, Biryukov S, Marczak L, et al. Global burden of hypertension and systolic blood pressure of at least 110 to $115 \mathrm{~mm}$ Hg, 1990-2015. JAMA. (2017) 317:165-82. doi: 10.1001/jama.2016.19043

2. Levy D, Garrison RJ, Savage DD, Kannel WB, Castelli WP. Prognostic implications of echocardiographically determined left ventricular mass in the framingham heart study. $N$ Engl J Med. (1990) 322:1561-6. doi: 10.1056/NEJM199005313222203

3. Lazzeroni D, Rimoldi O, Camici PG. From left ventricular hypertrophy to dysfunction and failure. Circ J. (2016) 80:555-64. doi: 10.1253/circj.CJ-16-0062

4. Drazner MH. The progression of hypertensive heart disease. Circulation. (2011) 123:327-34. doi: 10.1161/CIRCULATIONAHA.108.845792

5. Deschepper CF, Boutin-Ganache I, Zahabi A, Jiang Z. In search of cardiovascular candidate genes: interactions between phenotypes and genotypes. Hypertension. (2002) 39(2 Pt 2):332-6. doi: 10.1161/hy0202.102787

6. Chien KL, Hsu HC, Su TC, Chen MF, Lee YT. Heritability and major gene effects on left ventricular mass in the Chinese population: a family study. BMC Cardiovasc Disord. (2006) 6:37. doi: 10.1186/1471-2261-6-37

7. Tousoulis D, Androulakis E, Papageorgiou N, Miliou A, Chatzistamatiou E, Oikonomou E, et al. Genetic predisposition to left ventricular hypertrophy and the potential involvement of cystatin-c in untreated hypertension. Am J Hypertens. (2013) 26:683-90. doi: 10.1093/ajh/hps089

8. Arnett DK, Devereux RB, Rao D, Li N, Tang W, Kraemer R, et al. Novel genetic variants contributing to left ventricular hypertrophy: the hypergen study. $J$ Hypertens. (2009) 27:1585-93. doi: 10.1097/HJH.0b013e32832be612

9. Lavoie JL, Sigmund CD. Minireview: overview of the renin-angiotensin system - an endocrine and paracrine system. Endocrinology. (2003) 144:217983. doi: 10.1210/en.2003-0150

10. Manrique C, Lastra G, Gardner M, Sowers JR. The renin angiotensin aldosterone system in hypertension: roles of insulin resistance and oxidative stress. Med Clin North Am. (2009) 93:569-82. doi: 10.1016/j.mcna.2009.02.014

11. Bernstein KE, Ong FS, Blackwell WLB, Shah KH, Giani JF, GonzalezVillalobos RA, et al. A modern understanding of the traditional and nontraditional biological functions of angiotensin-converting enzyme. Pharmacol Rev. (2013) 65:1-46. doi: 10.1124/pr.112.006809

12. Cowan BR, Young AA. Left ventricular hypertrophy and reninangiotensin system blockade. Curr Hypertens Rep. (2009) 11:167-72. doi: 10.1007/s11906-009-0030-9
TM wrote the manuscript. All authors critically revised the manuscript.

\section{FUNDING}

This study was supported partially by the University of Medicine and Pharmacy at Ho Chi Minh City, Vietnam.

\section{SUPPLEMENTARY MATERIAL}

The Supplementary Material for this article can be found online at: https://www.frontiersin.org/articles/10.3389/fcvm. 2021.608948/full\#supplementary-material

Supplementary Figure 1 | Represented image of how echocardiography measurements were documented. IVSd, interventricular septal thickness at end-diastole; IVSs, interventricular septal thickness in systole; LPWd, posterior wall thickness at end-diastole; LPWs, posterior wall thickness in systole; LVIDd, left ventricular internal dimension at end-diastole; LVIDs, left ventricular internal dimension in systole.

Supplementary Table 1 | Primers for AGT M235T genotyping.

13. Jin Y, Kuznetsova T, Thijs L, Schmitz B, Liu Y, Asayama K, et al. Association of left ventricular mass with the AGTR1 A1166C polymorphism. Am J Hypertens. (2012) 25:472-8. doi: 10.1038/ajh.2011.244

14. Luo R, Li X, Wang Y, Li Y, Deng Y, Wan Y, et al. The influence of angiotensin converting enzyme and angiotensinogen gene polymorphisms on hypertrophic cardiomyopathy. PLoS ONE. (2013) 8:e77030. doi: 10.1371/journal.pone.0077030

15. Lynch AI, Tang W, Shi G, Devereux RB, Eckfeldt JH, Arnett DK. Epistatic effects of ACE I/D and AGT gene variants on left ventricular mass in hypertensive patients: the HyperGEN study. J Hum Hypertens. (2012) 26:13340. doi: 10.1038/jhh.2010.131

16. Brand E, Chatelain N, Paillard F, Tiret L, Visvikis S, Lathrop M, et al. Detection of putative functional angiotensinogen (AGT) gene variants controlling plasma AGT levels by combined segregation-linkage analysis. Eur J Hum Genet. (2002) 10:715-23. doi: 10.1038/sj.ejhg.5200874

17. Kooffreh ME, Anumudu CI, Akpan EE, Ikpeme EV, Lava Kumar P. A study of the M235T variant of the angiotensinogen gene and hypertension in a sample population of Calabar and Uyo, Nigeria. Egypt J Med Hum Genet. (2013) 14:13-9. doi: 10.1016/j.ejmhg.2012.06.007

18. Nakamura Y, Tabara Y, Miki T, Tamaki S, Kita Y, Okamura T, et al. Both angiotensinogen M235T and $\alpha$-adducin G460W polymorphisms are associated with hypertension in the Japanese population. J Hum Hypertens. (2007) 21:253-5. doi: 10.1038/sj.jhh.1002135

19. Say YH, Ling KH, Duraisamy G, Isaac S, Rosli R. Angiotensinogen M235T gene variants and its association with essential hypertension and plasma renin activity in Malaysian subjects: a case control study. BMC Cardiovasc Disord. (2005) 5:7. doi: 10.1186/1471-2261-5-7

20. Shamaa MM, Fouad H, Haroun M, Hassanein M, Hay MAA. Association between the angiotensinogen (AGT) gene (M235T) polymorphism and essential hypertension in Egyptian patients. Egypt Heart J. (2015) 67:1-5. doi: 10.1016/j.ehj.2013.10.001

21. Iwai N, Shimoike H, Ohmichi N, Kinoshita M. Angiotensinogen gene and blood pressure in the Japanese population. Hypertension. (1995) 25:688-93. doi: 10.1161/01.HYP.25.4.688

22. Procopciuc L, Popescu T, Jebeleanu G, Pop D, Zdrengehea D. Essential arterial hypertension and polymorphism of angiotensiongen M235T gene. J Cell Mol Med. (2002) 6:245-50. doi: 10.1111/j.1582-4934.2002.tb00191.x

23. Hingorani AD, Sharma P, Jia H, Hopper R, Brown MJ. Blood pressure and the M235T polymorphism of the angiotensinogen gene. Hypertension. (1996) 28:907-11. doi: 10.1161/01.HYP.28.5.907 
24. Mondry A, Loh M, Liu P, Zhu AL, Nagel M. Polymorphisms of the insertion / deletion ACE and M235T AGT genes and hypertension: surprising new findings and meta-analysis of data. BMC Nephrol. (2005) 6:1. doi: 10.1186/1471-2369-6-1

25. Jeng JR. Left ventricular mass, carotid wall thickness, and angiotensinogen gene polymorphism in patients with hypertension. Am J Hypertens. (1999) 12:443-50. doi: 10.1016/S0895-7061(99)00 006-0

26. Shlyakhto EV, Shwartz EI, Nefedova YB, Zukova AV, Vinnic TA, Conrady AO. Lack of association of the renin-angiotensin system genes polymorphisms and left ventricular hypertrophy in hypertension. Blood Press. (2001) 10:135-41. doi: 10.1080/080370501753182343

27. Tang W, Devereux RB, Rao DC, Oberman A, Hopkins PN, Kitzman DW, et al. Associations between angiotensinogen gene variants and left ventricular mass and function in the HyperGEN study. Am Heart J. (2002) 143:854-60. doi: $10.1067 / \mathrm{mhj} .2002 .121926$

28. Jacobi J, Schlaich MP, Delles C, Schobel HP, Schmieder RE. Angiotensin II stimulates left ventricular hypertrophy in hypertensive patients independently of blood pressure. Am J Hypertens. (1999) 12:418-22. doi: 10.1016/S0895-7061(98)00251-9

29. Executive summary of the clinical guidelines on the identification, evaluation, and treatment of overweight and obesity in adults. Arch Intern Med. (1998) 158:1855-67. doi: 10.1001/archinte.158.17.1855

30. Mosteller RD. Simplified calculation of body-surface area. $N$ Engl J Med. (1987) 317:1098. doi: 10.1056/NEJM198710223171717

31. D’Elia L, Obreja G, Ciobanu A, Breda J, Jewell J, Cappuccio FP. Sodium, potassium and iodine intake, in a national adult population sample of the republic of moldova. Nutrients. (2019) 11:2896. doi: 10.3390/nu11122896

32. Cluster WHOND, MH. WHO STEPS Surveillance Manual: The WHO STEPwise Approach to Chronic Disease Risk Factor Surveillance. World Health Organization (2005) Available online at: https://apps.who.int/iris/handle/ 10665/43376 (accessed September 6, 2020).

33. Williams B, Mancia G, Spiering W, Agabiti Rosei E, Azizi M, Burnier M, et al. 2018 ESC/ESH Guidelines for the management of arterial hypertensionThe Task Force for the management of arterial hypertension of the European Society of Cardiology (ESC) and the European Society of Hypertension (ESH). Eur Heart J. (2018) 39:3021-104. doi: 10.1093/eurheartj/ehy339

34. Lang RM, Badano LP, Mor-Avi V, Afilalo J, Armstrong A, Ernande L, et al. Recommendations for cardiac chamber quantification by echocardiography in adults: an update from the American Society of Echocardiography and the European Association of Cardiovascular Imaging. J Am Soc Echocardiogr. (2015) 28:1-39.e14. doi: 10.1016/j.echo.2014.10.003

35. Devereux RB, Alonso DR, Lutas EM, Gottlieb GJ, Campo E, Sachs I, et al. Echocardiographic assessment of left ventricular hypertrophy: comparison to necropsy findings. Am J Cardiol. (1986) 57:450-8. doi: 10.1016/0002-9149(86)90771-X

36. Teichholz LE, Kreulen T, Herman MV, Gorlin R. Problems in echocardiographic volume determinations: echocardiographic-angiographic correlations in the presence of absence of asynergy. Am J Cardiol. (1976) 37:7-11. doi: 10.1016/0002-9149(76)90491-4

37. Verdecchia P, Carini G, Circo A, Dovellini E, Giovannini E, Lombardo $\mathrm{M}$, et al. Left ventricular mass and cardiovascular morbidity in essential hypertension: the MAVI study. J Am Coll Cardiol. (2001) 38:1829-35. doi: 10.1016/S0735-1097(01)01663-1

38. Gidding SS, Carnethon MR, Daniels S, Liu K, Jacobs DR, Sidney S, et al. Low cardiovascular risk is associated with favorable left ventricular mass, left ventricular relative wall thickness, and left atrial size: the CARDIA study. J Am Soc Echocardiogr. (2010) 23:816-22. doi: 10.1016/j.echo.2010.05.023

39. Wu SJ, Chiang FT, Chen WJ, Liu PH, Hsu KL, Hwang JJ, et al. Three singlenucleotide polymorphisms of the angiotensinogen gene and susceptibility to hypertension: single locus genotype vs. haplotype analysis. Physiol Genomics. (2004) 17:79-86. doi: 10.1152/physiolgenomics.00133.2003
40. Le VS, Tran KT, Bui HTP, Le HTT, Nguyen CD, Do DH, et al. A Vietnamese human genetic variation database. Hum Mutat. (2019) 40:166475. doi: 10.1002/humu.23835

41. Do MD, Le LGH, Nguyen VT, Dang TN, Nguyen NH, Vu HA, et al. High-resolution HLA Typing of HLA-A, -B, -C, -DRB1, and -DQB1 in Kinh Vietnamese by Using Next-Generation Sequencing. Front Genet. (2020) 11:383. doi: 10.3389/fgene.2020.00383

42. Do MD, Pham DV, Le LP, Gia Le LH, Minh Tran LB, Dang Huynh MD, et al. Recurrent PROC and novel PROS1 mutations in Vietnamese patients diagnosed with idiopathic deep venous thrombosis. Int J Lab Hematol. (2020). doi: 10.1111/ijlh.13345. [Epub ahead of print].

43. Zhai C, Cong H, Zhang H, Hou K, Zhang Y, Zhang Y. M235T polymorphism in the angiotensinogen gene and cardiovascular disease: an updated metaanalysis of 39 case-control comparisons. Anatol J Cardiol. (2019) 21:222-32. doi: 10.14744/AnatolJCardiol.2019.75282

44. Watanabe T, Barker TA, Berk BC. Angiotensin II and the Endothelium. Hypertension. (2005) 45:163-9. doi: 10.1161/01.HYP.0000153321.13792.b9

45. Pereira AC, Mota GF, Cunha RS, Herbenhoff FL, Mill JG, Krieger JE. Angiotensinogen 235T allele "Dosage" is associated with blood pressure phenotypes. Hypertension. (2003) 41:25-30. doi: 10.1161/01.HYP.0000047465.97065.15

46. Lanz JR, Pereira AC, Lemos PA, Martinez E, Krieger JE. Angiotensinogen $\mathrm{M} 235 \mathrm{~T}$ polymorphism is associated with coronary artery disease severity. Clin Chim Acta Int J Clin Chem. (2005) 362:176-81. doi: 10.1016/j.cccn.2005.06.004

47. Pilbrow AP, Palmer BR, Frampton CM, Yandle TG, Troughton RW, Campbell E, et al. Angiotensinogen M235T and T174M gene polymorphisms in combination doubles the risk of mortality in heart failure. Hypertension. (2007) 49:322-7. doi: 10.1161/01.HYP.0000253061.30 170.68

48. Renner W, Nauck M, Winkelmann BR, Hoffmann MM, Scharnagl H, Mayer $\mathrm{V}$, et al. Association of angiotensinogen haplotypes with angiotensinogen levels but not with blood pressure or coronary artery disease: the ludwigshafen risk and cardiovascular health study. J Mol Med Berl Ger. (2005) 83:235-9. doi: 10.1007/s00109-004-0618-0

49. Inoue I, Nakajima $\mathrm{T}$, Williams CS, Quackenbush J, Puryear R, Powers $\mathrm{M}$, et al. A nucleotide substitution in the promoter of human angiotensinogen is associated with essential hypertension and affects basal transcription in vitro. J Clin Invest. (1997) 99:1786-97. doi: 10.1172/JCI1 19343

50. Sharma AM. The thrifty-genotype hypothesis and its implications for the study of complex genetic disorders in man. J Mol Med. (1998) 76:568-71. doi: $10.1007 /$ s001090050251

51. Nielsen R, Akey JM, Jakobsson M, Pritchard JK, Tishkoff S, Willerslev E. Tracing the peopling of the world through genomics. Nature. (2017) 541:30210. doi: $10.1038 /$ nature 21347

52. Lang RM, Addetia K, Narang A, Mor-Avi V. 3-Dimensional echocardiography: latest developments and future directions. JACC Cardiovasc Imaging. (2018) 11:1854-78. doi: 10.1016/j.jcmg.2018. 06.024

Conflict of Interest: The authors declare that the research was conducted in the absence of any commercial or financial relationships that could be construed as a potential conflict of interest.

Copyright (c) 2021 Tran, Mai, Tran, Le, Vu, Tran, Hoang, Chau and Do. This is an open-access article distributed under the terms of the Creative Commons Attribution License (CC BY). The use, distribution or reproduction in other forums is permitted, provided the original author(s) and the copyright owner(s) are credited and that the original publication in this journal is cited, in accordance with accepted academic practice. No use, distribution or reproduction is permitted which does not comply with these terms. 